\title{
Sistem Pakar Diagnosa Gangguan Kesehatan Akibat Tekanan Panas Terhadap Tubuh Dengan Metode Forward Chaining
}

\author{
Yovi Apridiansyah ${ }^{1}$, Ardi Wijaya ${ }^{2}$ \\ Program Studi Informatika, Fakultas Teknik, Universitas Muhammadiyah \\ Bengkulu \\ J. Bali, Bengkulu 38119 \\ yoviapridiansyah@umb.ac.id ${ }^{1}$ \\ ardiwijaya@umb.ac.id²
}

\begin{abstract}
Hot pressure occurs when the heat in the environment combined with other causes of stress such as heavy physical work, loss of fluids, fatigue or other medical conditions, which will cause heat-related illness, disability, and even death. Expert system is usually used to perform interpretation and analysis, diagnosis, and help decision-making, Forward chaining is a collection of data or facts to get the conclusions or results, of the background so it can be formulated problem was how to expert system to diagnose health disorders akiabt heat pressure against the body of the method using forward chaining. The purpose of this author is making an expert system that can help the user or the public to know what kind of diseases caused by the pressure of the heat, so that people can more easily know the disease suffered. The authors conducted a study at the Hospital of the city of Bengkulu Rafflesia. Time research was conducted from February 2018. Method of data collection by way of direct expert interview is concerned with object
\end{abstract}

Keywords: Expert System, Forward Chaining, Heat Pressure

Abstrak-Tekanan panas terjadi ketika panas di lingkungan dikombinasikan dengan penyebab stres lain seperti kerja fisik yang berat, kehilangan cairan tubuh, kelelahan atau kondisi medis lainnya, yang akan menyebabkan penyakit terkait panas, kecacatan, dan bahkan kematian. Sistem pakar biasanya digunakan untuk melakukan interpretasi dan analisa, diagnosa, dan membantu pengambilan keputusan, Forward chaining merupakan kumpulan data-data atau fakta untuk mendapatkan kesimpulan atau hasil, Dari latar belakang maka dapat dirumuskan permasalahannya adalah Bagaimana cara sistem pakar mendiagnosa gangguan kesehatan akiabt tekanan panas terhadap tubuh menggunakan metode forward chaining. Tujuan dari penulis ini adalah membuat suatu sistem pakar yang dapat membantu pengguna atau masyarakat untuk mengetahui jenis penyakit akibat tekanan panas, agar orang-orang bisa lebih mudah mengetahui penyakit yang diderita. Penulis melakukan penelitian di Rumah Sakit Rafflesia Kota Bengkulu. Waktu penelitian dilakukan dari bulan februari 2018. Metode pengumpulan data dengan cara mewawancari langsung pakar yang bersangkutan dengan objek 


\section{Keywords: Forward Chaining, Sistem Pakar, Tekanan Panas}

\section{Pendahuluan}

Perkembangan industri di dunia memunculkan permasalahan baru yang sifatnya menguntungkan dan juga merugikan baik dalam bidang ekonomi, sosial dan ketenagakerjaan. ILO (International Labour Organization) menyatakan bahwa setiap hari 6300 orang meninggal karena kecelakaan kerja atau penyakit terkait kerja dan 2,3 juta meninggal per tahun. Kerugian tahunan akibat kecelakaan kerja dan penyakit terkait kerja di beberapa negara mencapai 4 persen dari produk nasional bruto (PNB) [2].

Salah satu bahaya yang ada adalah adanya heat stress (tekanan panas) yang disebabkan proses produksi menggunakan temperatur tinggi. Heat stress atau tekanan panas terjadi ketika panas di lingkungan dikombinasikan dengan penyebab stres lain seperti kerja fisik yang berat, kehilangan cairan tubuh, kelelahan atau kondisi medis lainnya, yang akan menyebabkan penyakit terkait panas, kecacatan, dan bahkan kematian.

Heat strain merupakan dampak akut atau kronis yang diakibatkan tekanan panas yang dialami oleh seseorang dari aspek fisik maupun mental. Hal ini kemudian dapat menimbulkan beberapa penyakit atau keluhan yang berhubungan dengan panas, seperti heatcramps, heat exhaustion, atau pun heat stroke (National Safety Council, 2002) [3].

Manusia mempertahankan suhu inti tubuh tetap konstan sekitar $37^{\circ} \mathrm{C}$ agar organ-organ vital tubuh dapat terus berfungsi normal (Ministry of Bussines, Innovation and Employment, 2012).Fluktuasi suhu inti tubuh akibat aktifitas fisik dan suhu lingkungan tetap dijaga agar tetap dalam batas normal.Ketika fluktuasi suhu inti tubuh melebihi batas suhu normal beberapa gangguan kesehatan atau bahkan kematian dapat terjadi [1].

Pengetahuan tekanan panas setiap orang sangatlah sedikit. Orang-orang yang pengetahuannya sedikit hanya mengetahui bahwa penyakit yang dilanda tekanan panas itu semuanya sama, padahal penyakit yang diakibatkan oleh tekanan panas mempunyai banyak jenis. Oleh karena pengetahuan yang sedikit dapat mengakibatkan sakit yang lebih parah bahkan bisa sampai kematian.

Menggunakan metode forward chaining dengan langkah mengumpulkan fakta-fakta yang ada untuk menarik kesimpulan ( If Then ).Tujuan penelitian ini akan membantu pengetahuan akibat tekanan panas dan meminimalisirkan dampak yang akan terjadi. dengan harapan bila menggunakan system pakar ini akan membuat lebih mudah dalam mendiagnosa gangguan 
penyakit yang dinilai lebih praktis dibanding dengan cara manual.

\section{A. Sistem Pakar}

Sistem pakar adalah salah satu cabang dari kecerdasan buatan (Artificial Intelligence), yang merupakan suatu aplikasi komputerisasi yang berusaha menirukan proses penalaran dari seorang ahli dalam memecahkan masalah spesifik dan membuat suatu keputusan atau kesimpulan karena pengetahuannya disimpan di dalam basis pengetahuan untuk diproses pemecahan masalah. Dasar dari sistem pakar adalah bagaimana memindahkan pengetahuan yang dimiliki oleh seorang pakar ke komputer, dan bagaimana membuat keputusan serta mengambil kesimpulan berdasarkan pengetahuan itu [5]

\section{B. Tekanan Panas}

Tekanan panas merupakan kumpulan dari faktor lingkungan dan aktivitas fisik yang dapat meningkatkan jumlah panas di dalam tubuh.Faktor faktor lingkungan meliputi temperatur udara, perpindahan panas radiasi, pergerakan udara, dan tekanan parsial uap air (kelembaban). Aktivitas fisik yang mempunyai kontribusi terhadap total tekanan panas adalah aktivitas yang menyebabkan terjadinya peningkatan panas metabolik dalam tubuh sesuai dengan intensitas pekerjaan. Terjadinya tekanan panas adalah melalui kombinasi dari beberapa faktor (lingkungan, pekerjaan dan pakaian) dan cenderung untuk meningkatkan suhu inti tubuh, detak jantung/denyut nadi, dan keringat.Sedangkan menurut pengertian yang dikeluarkan oleh OSHA, tekanan panas adalah ketika terdapat suatu pekerjaan yang berhubungan dengan temperatur udara yang tinggi, radiasi dari sumber panas, kelembaban udara yang tinggi, pajanan langsung dengan benda yang mengeluarkan panas, atau aktifitas fisik secara terus menerus yang mempunyai potensi tinggi untuk menimbulkan tekanan panas.

\section{Forward Chaining}

Forward chaining atau sering juga disebut bottom up reasoning adalah cara penarikan kesimpulan yang dimulai dengan data atau fakta yang ada lalu bergerak maju melalui premispremis untuk menuju ke kesimpulan. Forward chaining merupakan fakta untuk mendapatkan kesimpulan (conclusion) dari fakta tersebut [4].

Metode ini adalah kebalikan metode Backward Chaining, dimana metode ini dijalankan dengan mengumpulkan fakta-fakta yang ada untuk menarik kesimpulan. Dengan kata lain, prosesnya dimulai dari facts (faktafakta yang ada) melalui proses interface fact (penalaran fakta-fakta) menuju suatu goal (suatu tujuan). Metode ini juga disebut menggunakan [6]. 


\begin{tabular}{|l|l|}
\hline No & \multicolumn{1}{|c|}{ Aturan } \\
\hline R-1 & IF A \& B THEN C \\
\hline R-2 & IF C THEN D \\
\hline R-3 & IF A \& E THEN F \\
\hline R-4 & IF A THEN G \\
\hline R-5 & IF F \& G THEN D \\
\hline R-6 & IF G \& E THEN H \\
\hline R-7 & IF C \& H THEN I \\
\hline R-8 & IF I \& A THEN J \\
\hline R-9 & IF G THEN J \\
\hline R-10 & IF J THEN K \\
\hline
\end{tabular}

\section{METODE PENELITIAN}

Dalam penelitian ini model $\begin{array}{llr}\text { pengembangan } & \text { sistem } & \text { yang } \\ \text { digunakan } & \text { yaitu } & \text { model }\end{array}$ incremental.Incremental model adalah model pengembangan sistem pada rekayasa perangkat lunak berdasarkan perangkat lunak persyaratan yang dipecah menjadi beberapa fungsi atau bagian sehingga model pengembangannya secara bertahap.

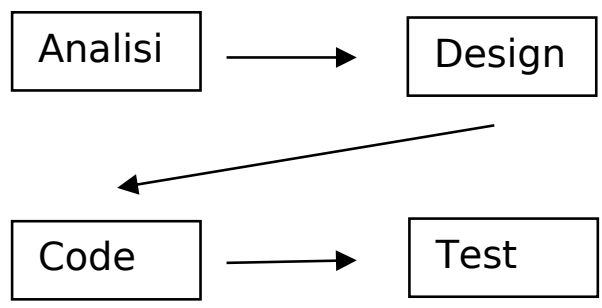

Gambar 1. Diagram Konteks

\section{A. Analisis}

Analisis data diartikan sebagai upaya mengolah data menjadi informasi, sehingga karakteristik atau sifat-sifat data tersebut dapat dengan mudah dipahami dan bermanfaat untuk menjawab masalah-masalah yang berkaitan dengan kegiatan penelitian.

\section{B. Design}

Dalam tahapan design ini Menghasilkan rancangan yang memenuhi kebutuhan yang ditentukan selama tahapan analisis. Hasil akhirnya berupa spesifikasi rancangan yang sangat rinci sehingga mudah diwujudkan . Login admin .semrograman.

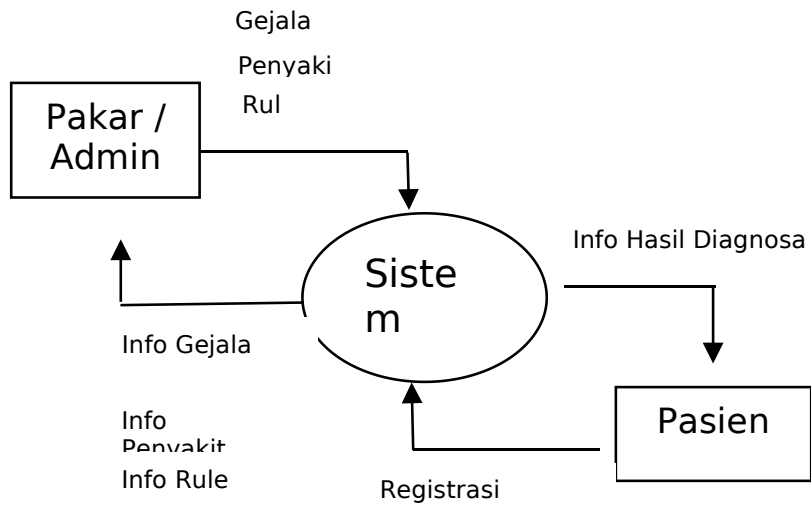

\section{Code}

Pengkodean yang mengimplementasikan hasil desain kedalam kode atau bahasa yang dimengerti oleh mesin komputer dengan menggunakan bahasa pemrograman Web.

Penulisan kode program merupakan tahap penerjemahandesain sistem yang telah dibuat ke dalam bentuk perintah-perintah yang dimengerti komputer denganmempergunakan bahasa pemrograman, dan databasetertentu di atas platform yang menjadi standar perusahaan.Pada penelitian ini bahasa pemrograman 
yang digunakan adalah PHP dengan database MySQL.

\section{Test}

Dalam tahapan test ini merupakan proses lanjutan dari pengcodean program yang di buat. Dalam tahapan ini user melakukan pengujian dengan metode pengujian yang dipakai adalah black box testing. black box testing atau test fungsional adalah pengujian program yang dilakukan oleh pengembang (Programmer) dengan memberikan input tertentu dan melihat hasil yang didapatkan dari input tersebut. dengan kata lain, black box testing terfokus pada fungsionalitas sistem.

\section{HASIL DAN PEMBAHASAN}

Pada tahap implementasi sistem, rancangan dan desain sistem diimplementasikan dengan bahasa pemrograman menggunakan bahasa pemrograman PHP My SQL dengan hasil dari data-data yang telah didapatkan

Tabel 1. Tabel Penyakit

\begin{tabular}{|c|l|}
\hline $\begin{array}{c}\text { Kod } \\
\text { e }\end{array}$ & \multicolumn{1}{|c|}{ Penyakit } \\
\hline P1 & Heat Cramps / Kram Panas \\
\hline P2 & Heat Syncope / Pingsan Panas \\
\hline P3 & $\begin{array}{l}\text { Heat Exhaustion / Kelelahan } \\
\text { Panas Parah }\end{array}$ \\
\hline P4 & Heat Stroke / Sengatan Panas \\
\hline
\end{tabular}

\begin{tabular}{|c|l|}
\hline $\begin{array}{c}\text { Kod } \\
\text { e }\end{array}$ & \multicolumn{1}{|c|}{ Gejala } \\
\hline G01 & Suhu Tubuh < $37^{\circ} \mathrm{C}$ \\
\hline G02 & $\begin{array}{l}\text { Detak Jantung Berdetak Cepat } \\
\text { dan Terkadang Lemah }\end{array}$ \\
\hline G03 & Tidak Ada Gejala \\
\hline G04 & Suhu Tubuh 37 - 40 ${ }^{\circ} \mathrm{C}$ \\
\hline G05 & Suhu Tubuh > 40 ${ }^{\circ} \mathrm{C}$ \\
\hline G06 & Kejang - kejang \\
\hline G07 & Kram \\
\hline G08 & Penurunan Kesadaran \\
\hline G09 & Pingsan \\
\hline G10 & Mual / Muntah / Diare \\
\hline G11 & Pucat \\
\hline G12 & Tekanan Darah Rendah \\
\hline G13 & Vertigo / Pusing \\
\hline G14 & Laju Pernafasan Meningkat \\
\hline G15 & $\begin{array}{l}\text { Kulit Dingin , Lembab dan } \\
\text { Merinding Terkena Panas }\end{array}$ \\
\hline
\end{tabular}

Tabel 3. Tabel Rule

\begin{tabular}{|c|l|c|}
\hline $\begin{array}{c}\text { Rul } \\
\text { e }\end{array}$ & \multicolumn{1}{|c|}{ Rule } & Penyakit \\
\hline R1 & G02, G04, G07 & P1 \\
\hline R2 & $\begin{array}{l}\text { G02, G04, G08, } \\
\text { G09, G11 }\end{array}$ & P2 \\
\hline R3 & $\begin{array}{l}\text { G02, G04, G08, } \\
\text { G10, G11, G12,G13 }\end{array}$ & P3 \\
\hline R4 & $\begin{array}{l}\text { G02, G05, G06, } \\
\text { G08, G11,G12, G13, } \\
\text { G14,G15 }\end{array}$ & P4 \\
\hline
\end{tabular}

A. Menu Utama

Tabel 2. Tabel Gejala 


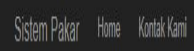

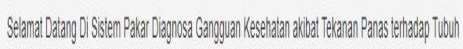

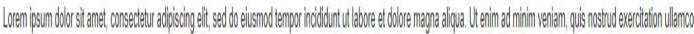

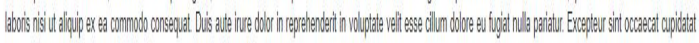

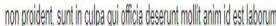

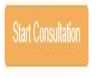

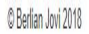

\section{Gambar 2. Tampilan Menu Utama}

Tampilan menu utama ini menampilkan halaman awal program yang berisi memulai untuk konsultasi

B. Menu Registrasi

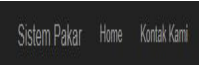

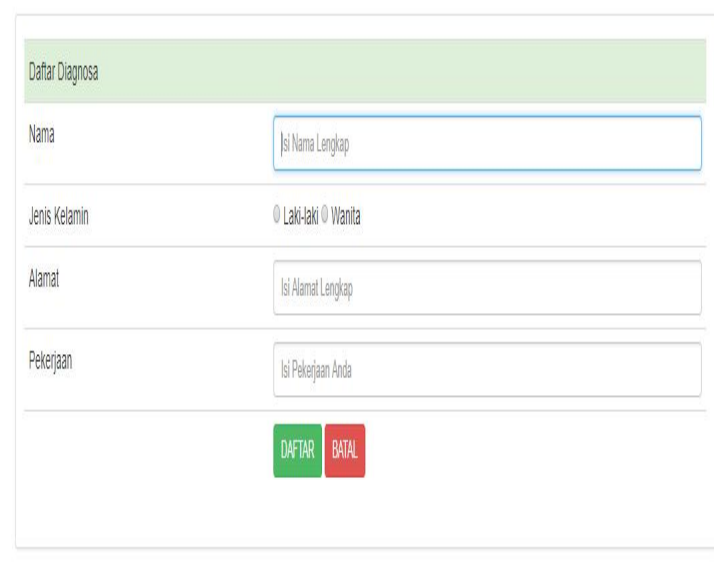

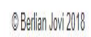

\section{Gambar 3. Tampilan Menu Registrasi}

Tampilan ini muncul sesaat memulai konsultasi, diisi terlebih dahulu sebelum memulai konsultasi kedalam sistem

\section{Menu Konsultasi}

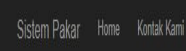

JAMABLAH PERTANAAN BERIUT

Apkakh Sultut thoth 37-40?

Benr: (Y)

Salah TDHK

LANI!

BBailanowi2018

\section{Gambar 4.Menu Konsultasi}

Prosesini dimana para konsultan menjawab pertanyaan yang telah di sediakan system untuk mendapatkan hasil di akhir konsultasi.

D. Menu Hasil Konsultasi

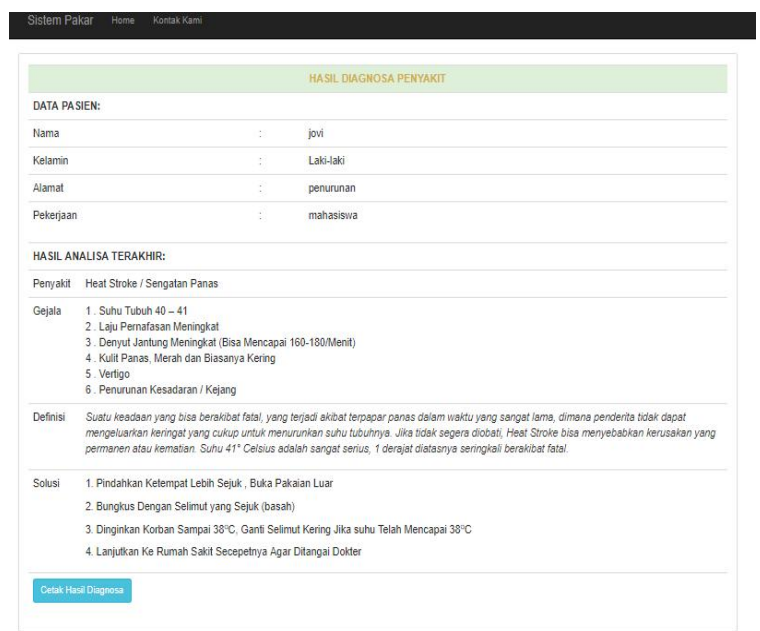

\section{Gambar 5.Tampilan Menu Hasil Konsultasi}

Tampilan ini menunjukan hasil dari konsultasi yang telah di jawab konsultan dan akan memberi tahu 
penyakit yang diderita serta defini dan solusi.

\section{Pengujian Sistem}

Pada penelitian ini pengujian sistem menggunakan Blackbox testing merupakan salah satu metode pengujian perangkat lunak yang berfokus pada sisi fungsionalitas, khususnya pada outputprogram (apakah sudah sesuai dengan apa yang diharapkan atau belum). Tahap pengujian atau testing merupakan salah satu tahap yang harus ada dalam sebuah siklus pengembangan perangkat lunak (selain tahap perancangan atau desain).

Tabel 4. Pengujian Black box

\begin{tabular}{|c|c|c|c|c|}
\hline \multirow{2}{*}{$\begin{array}{l}\mathrm{N} \\
\mathrm{O}\end{array}$} & \multirow{2}{*}{$\begin{array}{l}\text { Gejala } \\
\text { yang di } \\
\text { input }\end{array}$} & \multicolumn{2}{|c|}{ Hasil Diagnosa } & \multirow{2}{*}{$\begin{array}{l}\text { Kete } \\
\text { rang } \\
\text { an }\end{array}$} \\
\hline & & $\begin{array}{l}\text { Progra } \\
\mathrm{m}\end{array}$ & Pakar & \\
\hline 1 & $\begin{array}{l}\text { Suh } \\
u<37 \\
\text { Derajat C }\end{array}$ & $\begin{array}{l}\text { Anda } \\
\text { Tidak } \\
\text { Sakit } \\
\text { Tekana } \\
\text { n } \\
\text { Panas }\end{array}$ & $\begin{array}{l}\text { Pasien } \\
\text { Tidak } \\
\text { Sakit } \\
\text { Tekana } \\
\text { n } \\
\text { Panas }\end{array}$ & Valid \\
\hline 2 & $\begin{array}{l}\quad \text { Det } \\
\text { ak Jantung } \\
\text { Berdetak } \\
\text { Lemah } \\
\text { dan Cepat } \\
\quad \text { Suh } \\
\text { u Tubuh } \\
37-40^{\circ} \mathrm{C} \\
\text { Kram }\end{array}$ & $\begin{array}{l}\text { Heat } \\
\text { Cramp } \\
\text { S / } \\
\text { Kram } \\
\text { Panas }\end{array}$ & $\begin{array}{l}\text { Heat } \\
\text { Cramp } \\
\text { s / } \\
\text { Kram } \\
\text { Panas }\end{array}$ & Valid \\
\hline 3 & $\begin{array}{l}\text { Detak } \\
\text { Jantung }\end{array}$ & Heat & Heat & Valid \\
\hline
\end{tabular}

\begin{tabular}{|c|c|c|c|c|}
\hline & $\begin{array}{l}\text { Berdetak } \\
\text { Lemah } \\
\text { dan Cepat } \\
\text { Suhu } \\
\text { Tubuh 37- } \\
40^{\circ} \mathrm{C} \\
\text { Penuruna } \\
\mathrm{n} \\
\text { Kesadaran } \\
\text { Mual/Munt } \\
\text { ah/Diare } \\
\text { Pingsan } \\
\quad \text { Puc } \\
\text { at }\end{array}$ & $\begin{array}{l}\text { Syncop } \\
\text { e / } \\
\text { Pingsa } \\
\text { n } \\
\text { Panas }\end{array}$ & $\begin{array}{l}\text { Syncop } \\
\text { e / } \\
\text { Pingsa } \\
\text { n } \\
\text { Panas }\end{array}$ & \\
\hline 4 & $\begin{array}{l}\text { Detak } \\
\text { Jantung } \\
\text { Berdetak } \\
\text { Lemah } \\
\text { dan Cepat } \\
\text { Suhu } \\
\text { Tubuh 37- } \\
\text { 40 C } \\
\text { Mual/Munt } \\
\text { ah/Diare } \\
\text { Pucat } \\
\text { Tekanan } \\
\text { Darah } \\
\text { Rendah } \\
\text { Vertigo / } \\
\text { Pusing }\end{array}$ & $\begin{array}{l}\text { Heat } \\
\text { Exhaus } \\
\text { tion / } \\
\text { Kelelah } \\
\text { an } \\
\text { panas }\end{array}$ & $\begin{array}{l}\text { Heat } \\
\text { Exhaus } \\
\text { tion / } \\
\text { Kelelah } \\
\text { an } \\
\text { panas }\end{array}$ & Valid \\
\hline 5 & $\begin{array}{l}\text { Detak } \\
\text { Jantung } \\
\text { Berdetak } \\
\text { Lemah } \\
\text { dan Cepat } \\
\text { Suhu } \\
\text { Tubuh > } \\
40^{\circ} \mathrm{C} \\
\text { Kejang - } \\
\text { kejang } \\
\text { Penuruna } \\
\text { n } \\
\text { Kesadaran } \\
\text { Pucat } \\
\text { Tekanan } \\
\text { Darah } \\
\text { Rendah } \\
\text { Vertigo / } \\
\text { Pusing }\end{array}$ & $\begin{array}{l}\text { Heat } \\
\text { Stroke } \\
\text { / } \\
\text { Sengat } \\
\text { an } \\
\text { Panas }\end{array}$ & $\begin{array}{l}\text { Heat } \\
\text { Stroke } \\
\text { / } \\
\text { Sengat } \\
\text { an } \\
\text { Panas }\end{array}$ & Valid \\
\hline
\end{tabular}




\begin{tabular}{|l|l|l|l|l|}
\hline & Laju & & & \\
Pernafasa & & & & \\
$\mathrm{n}$ & & & \\
Meningkat & & & \\
Kulit & & & \\
dingin, & & & \\
lembab & & & \\
dan & & & \\
merinding & & & \\
terkena & & & \\
panas & & & \\
& & & & \\
\hline
\end{tabular}

\section{KESIMPULAN}

Dari hasil penelitian ini dapat ditarik kesimpulan sebagai berikut :

1. Dengan menggunakan metode forward chaining sistem ini dapat mencari penyakit tekanan panas dari pasien, sehingga pasien dapat mencari sendiri penyakit yang diderita.

2. Aplikasi ini dapat membantu memberikan kemudahan pihak Rumah Sakit Rafflesia Kota Bengkulu dalam mendiagnosa penyakit tekanan panas.

\section{SARAN}

Dengan adanya penelitian ini, diharapkan adanya sebuah sistem dapat memberikan kemudahan dalam mendiagnosa penyakit tekanan panas. Untuk itu penulis saran dari penelitian yang telah dilakukan diantaranya adalah sebagai berikut :

1. Aplikasi ini dapat digunakan oleh pihak Rumah Sakit Rafflesia Kota Bengkulu sebagai sarana pembantu dalam pelaksanaan dalam pendiagnosaan terhadap penyakit tekanan panas.

2. Aplikasi ini perlu dikembangkan lebih lanjut menjadi sistem pakar yang menggunakan metode lain dan dapat ditambah dengan gejala serta penyakit baru

\section{DAFTAR PUSTAKA}

[1] Abdani Fauzi, Zahro 2013.FaktorFaktor yang Berhubungan dengan Suhu Tubuh Pekerja Pabrik Tahu. Ciputat

[2] Defi Saputri, Zarah 2014. Analisis Pajanan Tekanan Panas dan Keluhan Subjektif Pada Pekerja di Bagian Produksi PT Frisian Flag Indonesia Plant Ciracas Tahun 2014.Ciracas

[3] Fadhilah, Rizki 2014. Faktor-Faktor yang Berhubungan Dengan Heat Strain pada Pekerja Pabrik Kerupuk. Ciputat Timur.

[4] Feby Nur. Dkk, 2015.Sistem Pakar Penentuan Bakat Anak dengan Menggunakan Metode Forward Chaining. Padang

[5] Ongko, Erianto 2013. Perancangan Sistem Pakar Diagnosa Penyakit pada Mata. Medan.

[6] Supartini, Windah., Hindarto 2016.Sistem Pakar Berbasis Web Dengan Metode Forward Chaining 
Dalam Mendiagnosis Dini Penyakit

Tuberkulosis di JawaTimur. Sidoarjo 
